\title{
PENGARUH TEKNIK STIMULASI PUTING SUSU TERHADAP LAMA PERSALINAN KALA I
}

\author{
Sih Rini Handajani, KH Endah Widhi Astuti \\ Kementerian Kesehatan Politeknik Kesehatan Surakarta Jurusan Kebidanan
}

\begin{abstract}
Nipple Stimulation, Labor Kala I. The purpose of this study was to determine the influence of nipple stimulation techniques of the duration of labor in the first stage in Puskesmas Gajahan Surakarta. This research is a quasi experimental with posttest design with control group. The population in this study is that maternal primigravid active phase of the first stage in the clinic Gajahan Surakarta. Samples were taken by accidental sampling technique. Based on the estimation formula of the samples obtained a total sample of 62 women giving birth. 31 maternal treated with nipple stimulation, while 31 as the control group with the mobilization of the left oblique. Data collection using observation sheet implementation nipple stimulation and sheets partograf to observe the first stage of labor longer active phase. The average length of first stage of labor in the control group maternity primigravida who did nipple stimulation (mobilization) in Puskesmas Gajahan is 3:36 minutes, the average length of first stage of labor in the treatment group maternity primigravida who do nipple stimulation in Puskesmas Gajahan is 3:21 minutes and no influence of nipple stimulation to the first stage of labor longer with $p$ value $=-0.295$ ( $p<0.05)$, so Ho accepted because $-0.295<2.002$. Nipple stimulation has an influence on the first stage in a long time Gajahan Surakarta Health Center.
\end{abstract}

Keywords: Nipple Stimulation, Labor Kala I.

Abstrak: Stimulasi Puting Susu, Persalinan Kala I. Tujuan penelitian ini adalah untuk mengetahui pengaruh teknik pemberian stimulasi puting susu dengan lama persalinan pada kala I di Puskesmas Gajahan Surakarta. Penelitian ini merupakan penelitian quasi eksperimen dengan desain posttest with control group. Populasi dalam penelitian ini ialah ibu bersalin primigravida kala I fase aktif di puskesmas Gajahan Surakarta. Sampel diambil dengan teknik accidental sampling. Berdasar rumus estimasi besar sampel didapatkan jumlah sampel sebanyak 62 ibu bersalin. $31 \mathrm{ibu}$ bersalin diberi perlakuan dengan stimulasi puting susu, sedangkan 31 sebagai kelompok kontrol dengan mobilisasi miring kiri. Pengumpulan data dengan menggunakan lembar observasi pelaksanaan stimulasi puting susu dan lembar partograf untuk mengamati lama persalinan kala I fase aktif. Rata-rata lama persalinan kala I pada kelompok kontrol ibu bersalin primigravida yang tidak melakukan stimulasi puting susu (mobilisasi) di Puskesmas Gajahan adalah 3.36 menit, rata-rata lama persalinan kala I pada kelompok perlakuan ibu bersalin primigravida yang melakukan stimulasi puting susu di Puskesmas Gajahan adalah 3.21 menit dan ada pengaruh stimulasi puting susu terhadap lama persalinan kala 1 dengan $\mathrm{p}$ value $=-0,295(\mathrm{p}<0,05)$ sehingga Ho diterima karena $-0,295<2,002$. Stimulasi puting susu mempunyai pengaruh terhadap lama kala I di Puskesmas Gajahan Surakarta. 
Kata Kunci: Stimulasi Puting Susu, Persalinan Kala I.

\section{PENDAHULUAN}

Making Pregnancy Safer (MPS) merupakan salah satu upaya Kementerian Kesehatan Republik Indonesia (Kemenkes RI) dalam menurunkan Angka Kematian Ibu (AKI) dan Angka Kematian Bayi (AKB). Salah satu dari 3 pesan kunci MPS tersebut adalah setiap persalinan ditolong oleh tenaga kesehatan terlatih. Menurut Bina Pelayanan Medik (2010: 11) kematian ibu selama masa perinatal merupakan tolok ukur kemampuan pelayanan kesehatan suatu negara dan merupakan salah satu indikator spesifik status kesehatan suatu masyarakat. Mortalitas dapat dilihat dari indikator AKI dan $\mathrm{AKB}$, hal ini sesuai dengan kesepakatan dalam Millenium Development Goals (MDG's) 2015 yang merupakan kesepakatan dari 189 negara termasuk Indonesia.

Adapun tujuan pembangunan MDG's no 4 dan 5 tersebut antara lain menurunkan angka kematian bayi dan meningkatkan kesehatan ibu. Upaya kesehatan maternal dilakukan secara sistematik untuk mengurangi resiko kematian, menjamin reproduksi sehat dan meningkatkan kualitas hidup ibu (Depkes, 2011). Sejatinya proses persalinan persalinan merupakan proses yang sangat dinantikan oleh setiap ibu hamil, akan tetapi tidak semua persalinan yang dinantikan tersebut dapat berjalan dengan lancar. Tidak jarang proses persalinan berakhir dengan kematian ibu atau bayi.

Indonesia telah menetapkan target penurunan AKI menjadi 102/100.000 kelahiran hidup dan AKB menjadi 23/1000 kelahiran hidup pada tahun 2015. Sedangkan menurut hasil Survei
Demografi dan Kesehatan Indonesia (SDKI tahun 2013) AKB sudah mengalami penurunan dari 34/1000 kelahiran hidup pada tahun 2007 menjadi 32/1000 kelahiran hidup dan AKI tahun 2013 sebesar 359 per 100.000 kelahiran hidup dan masih dibawah pencapaian target tahun 2014 yaitu 118 kasus per 100.000 kelahiran hidup (Dinas Kesehatan Jawa Tengah, 2013). Dinas Kesehatan Jawa Tengah tahun 2013 menyatakan bahwa AKI mencapai 675 kasus dan cenderung meningkat dibandingkan dengan tahun sebelumnya, atau setiap jam terdapat 2 orang ibu bersalin meninggal karena berbagai sebab.

Persalinan merupakan proses pergerakan keluarnya janin, plasenta dan membran amnion dari dalam rahim melalui jalan lahir (Bobak, 2005). Kontraksi uterus dipengaruhi oleh pengeluaran oksitosin. Menurut Widyastuti (2001) seperti dikutip Yunita (2010:) stimulasi puting susu secara alamiah dapat membantu proses pengeluaran oksitosin. Oksitosin mempengaruhi otot polos uterus.Oksitosin meningkatkan frekuensi dan durasi potensial aksi, jadi pemberian oksitosin merangsang timbulnya kontraksi otot uterus yang belum berkontraksi dan meningkatkan kekuatan serta frekuensi kontraksi otot pada uterus yang sudah berkontraksi (Francis dan John, 2000). Stimulasi puting susu pada ibu bersalin dilakukan jari.

Berdasarkan studi pendahuluan di didapatkan data bahwa ibu bersalin pada kala I tidak dilakukan stimulasi puting susu, sehingga lama persalinan kala I fase aktif rata-rata berkisar antara 6,5 sampai 7 
jam. Stimulasi biasanya hanya dilakukan pada kala II saja. Berdasarkan latar belakang tersebut peneliti tertarik untuk meneliti pengaruh teknik pemberian stimulasi puting susu dengan lama persalinan pada kala I di Puskesmas Gajahan Surakarta.

\section{METODE PENELITIAN}

Dilihat dari ada tidaknya intervensi terhadap salah satu variabel penelitian, jenis penilitian ini adalah penelitian quasi eksperimen. Peneliti memberikan perlakuan dengan membandingkan dua kelompok subyek yang diteliti, peneliti melakukan perlakuan terhadap subyek penelitian, sedangkan faktor yang lain tidak dimanipulasi (Siswanto, 2013: 28).

Desain penelitian yang digunakan adalah pre-experimental dengan rancangan static-group comparison. Pelaksanaan penelitian ini membagi subyek penelitian dalam dua kelompok yaitu kelompok untuk perlakuan dan setengahnya sebagai kelompok kontrol.

\section{HASIL PENELITIAN}

Pengambilan data dilakukan selama kurang lebih 2 bulan dari bulan April-Mei 2015 mengambil lokasi di Puskesmas Gajahan kota Surakarta. Puskesmas Gajahan merupakan salah satu Puskesmas di kota Surakarta yang terletak di bagian selatan sdengan fasilitas rawat inap dan merupakan salah satu Puskesmas yang sangat sibuk dengan rata rata persalinan per bulan antara 30 sd 50 pasien. Puskesmas ini juga banyak menampung pasien pasien ibu bersalin dari wilayah Sukoharo karena letaknya yang berbatasan dengan Kabupaten Sukoharjo.

\section{Tabel 1}

\section{Distribusi Frekuensi Kelompok \\ Perlakuan}

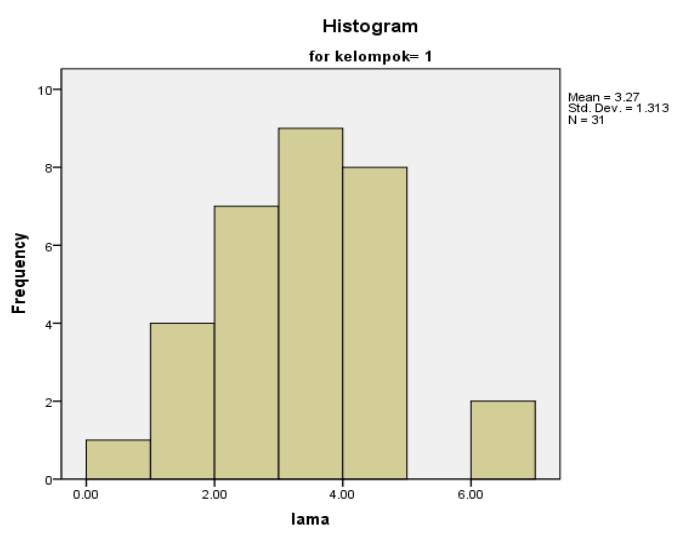

Berdasarkan gambar di atas, maka dapat dijelaskan bahwa kemajuan persalinan dicapai paling cepat selama 0,92 jam (55 menit) dan paling lama 6,82 jam(6 jam 50 menit), dengan rerata 3.27 jam dan simpangan bakunya1.313.

\section{Tabel 2}

\section{Distribusi Frekuensi Kelompok Kontrol (mobilisasi)}

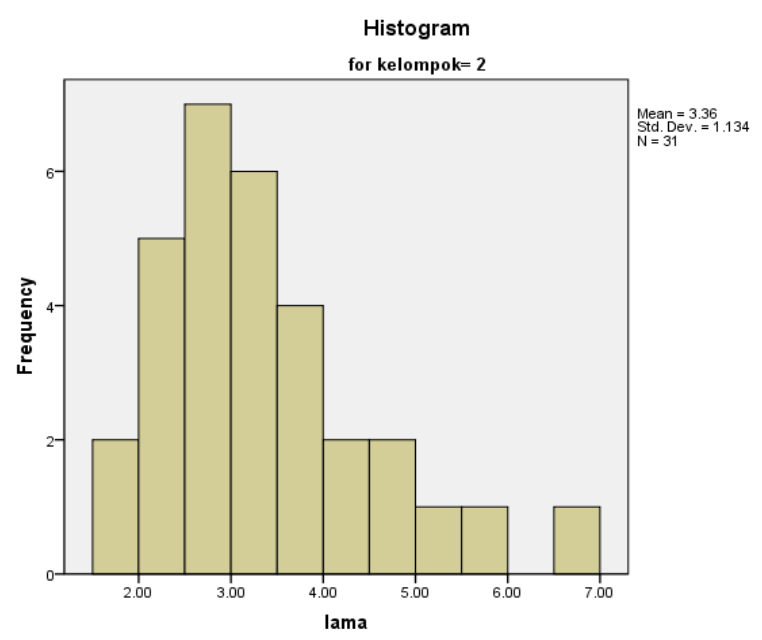


Berdasarkan gambar di atas, maka dapat dijelaskan bahwa kemajuan persalinan dicapai paling cepat selama 1,75 jam (1 jam 45 menit) dan paling lama 6,5 jam (6 jam 30 menit), dengan rerata 3.36 jam dan simpangan bakunya1.134.

\section{Tabel 3}

Distribusi Frekuensi Kelompok Perlakuan dan Kelompok Kontrol Stimulasi Puting Susu

\begin{tabular}{llll}
\hline NO & INDIKATOR & KELOMPOK & KELOMPOK \\
& KEMAJUAN & 1 & 2 \\
\hline 1. & Paling cepat & 0,92 & 1,75 \\
2. & Paling lama & 6,82 & 6,5 \\
3. & Rerata & 3,27 & 3,36 \\
4. & S. Baku & 1,313 & 1,134 \\
\hline
\end{tabular}

Tabel diatas menunjukkan bahwa rata-rata lama persalinan kala 1 pada kelompok perlakuan yang melakukan stimulasi puting susu adalah 3.27 atau 3 jam 16 menit sedangkan pada kelompok kontrol yang melakukan mobilisasi adalah 3.36 menit atau 3 jam 22 menit. Hal tersebut terlihat lama persalinan kala 1 fase aktif kelompok dengan perlakuan stimulasi puting susu lebih cepat daripada kelompok kontrol yang melakukan mobilisasi.

\section{Tabel 4}

Analisa t-test Pengaruh Teknik Pemberian Stimulasi Puting Susu Terhadap Lama Persalinan Kala I

\begin{tabular}{|c|c|c|c|c|c|}
\hline & & $\mathrm{F}$ & Sig. & $\mathrm{T}$ & Df \\
\hline \multirow[t]{2}{*}{ Lama } & $\begin{array}{l}\text { Equal } \\
\text { variances } \\
\text { assumed }\end{array}$ & .671 & .416 & -.295 & 60 \\
\hline & $\begin{array}{l}\text { Equal } \\
\text { variances } \\
\text { not } \\
\text { assumed }\end{array}$ & & & $\begin{array}{l}- \\
.295\end{array}$ & 58.752 \\
\hline
\end{tabular}

Berdasarkan tabel di atas, nilai signifikansi sebesar $0,416>0,05$ maka dinyatakan Ho diterima artinya bahwa pada kelompok 1 (perlakuan) maupun kelompok 2 (kontrol) adalah sama.

Selanjutnya hipotesis diuji dengan uji " $t$ " menggunakan Equal Variances Assumed (diasumsikan kedua varian sama) dengan pengujian dengan menggunakan uji 2 sisi pada tingkat signifikansi $\alpha=0,05$. Berdasarkan tabel di atas didapatkan bahwa : dengan thitung 0,295 sedangkan t tabel pada dk n-2 (60) adalah 2.000 sehingga Ho diterima karena $-0,295<2,002$

\section{PEMBAHASAN}

Persalinan merupakan proses normal, berupa kontraksi uterus involunter efektif dan terkoordinasi, yang menyebabkan penipisan dan dilatasi serviks progresif disertai penurunan dan kelahiran bayi serta plasenta (Benson dan Pernoll, 2009: 149). Sedangkan persalinan kala I adalah kala pembukaan yang berlangsung antara pembukaan 0 (nol) sampai pembukaan lengkap $(10 \mathrm{~cm})$. Faktor- faktor yang terlibat didalam mulainya persalinan adalah faktor hormonal dan faktor distensi uterus. Faktor hormonal yaitu hormon progesteron yang dihasilkan oleh plasenta. Oksitosin yang dikeluarkan oleh kelenjar pituitari posterior dari ibu, juga oleh janin, estrogen, kortisol dihasilkan oleh bagian korteks adrenal janin, prostaglandin yang dihasilkan dari desidua uteri dan selaput janin. Secara teori payudara yang dirangsang akan melepaskan hormon oksitosin yang dapat menyebabkan kontraksi, hormon oksitosin yang dapat menyebabkan persalinan yang dapat dihasilkan secara alamiah yaitu dengan stimulasi puting susu pada ibu (Chapman, 2006 : 99). Stimulasi puting (nipple stimulation) adalah menggosok, memijat atau melakukan gerakan melingkar di 
daerah puting dengan lembut yang diyakini bisa mendorong terjadinya kontraksi awal.

Hasil penelitian dari $62 \mathrm{ibu}$ bersalin primigravida menunjukkan bahwa ibu bersalin primigravida yang melakukan stimulasi puting susu dan mengalami fase aktif yang cepat $(\leq 360$ menit) adalah 31 orang $(100 \%)$. Sedangkan ibu bersalin primigravida yang melakukan mobilisasi (kontrol) dan mengalami fase aktif cepat adalah 14 orang $(45,6 \%)$ serta ibu bersalin primigravida yang melakukan mobilisasi mengalami fase aktif memanjang sebanyak 17 (54,8\%) orang. Prinsip kerja hormon oksitosin adalah dengan cara menstimulasi kontraksi sel otot polos pada rahim wanita hamil selama melahirkan dan menstimulasi kontraksi sel-sel kontraktil dari kelenjar susu agar mengeluarkan air susu. Perangsangan puting susu menghasilkan reflek neurohumoral. Oksitosin meyebabkan kontraksi sel, sejumlah stimulus juga merangsang pelepasan ADH seperti peningkatan osmolalitas plasma dan hipovolemia menyebabkan sekresi oksitosin (Francis dan John, 2000).

Salah satu cara efektif untuk merangsang kontraksi uterus adalah dengan stimulasi puting susu dengan cara mengusap salah satu atau kedua puting dengan lembut, berhenti selama ada kontraksi dan mengusapnya lagi sesudah kontraksi berhenti. Chapman, 2006 dalam bukunya menyebutkan bahwa merangsang puting menyebabkan keluarnya oksitosin yang menimbulkan kontraksi rahim. Rangsangan yang diberikan pada puting susu bisa membantu proses kelahiran. Ibu dapat menggosok puting susu karena akan meningkatkan kontraksi uterus dengan rangsangan alamiah. Berdasarkan teori puting susu disusun oleh urat-urat otot yang lembut dan merupakan sebuah jaringan yang tebal berupa urat saraf berada di ujungnya, rangsangan yang diberikan pada puting susu bisa membantu proses kelahiran (Mayasara, 2011). Apabila terjadi rangsangan mekanisme ujung syaraf pada puting susu dan areola mammae, rangsangan itu nantinya akan diteruskan ke bagian hipotalamus dan menyebabkan hipofise posterior mensekresikan oksitosin ke dalam peredaran darah antara lain miometrium (Chapman, 2006: 100). Sebagian besar rangsangan puting susu telah diselidiki kegunaannya sebagai alternatif oksitosin pada tes stres kontraksi (suatu tes yang telah ditetapkan tampak tidak efektif dan berbahaya) dan efektifitasnya dalam melunakkan serviks dan menginduksi persalinan (Simkin dan Acheta, 2005). Stimulasi puting susu bisa memberikan efek yang kuat, mirip seperti oksitosin buatan (sintetis) yang sering dipakai saat induksi persalinan hal ini di buktikan bahwa dalam penelitian ini waktu paling cepat kala1 pada ibu yang melakukan stimulasi putting susu adalah 55 menit dimana hal ini lebih cepat dari persalinan ibu kala 1 dimana Menurut (Prawirohardjo, 2009: 323) Fase laten terjadi selama 8 jam dimana pembukaan serviks $0 \mathrm{~cm}$ sampai pembukaan $3 \mathrm{~cm}$ dan fase aktif selama 6 jam dimana pembukaan serviks $4 \mathrm{~cm}$ sampai pembukaan $10 \mathrm{~cm}$. Sehingga dapat disimpulkan bahwa pada primigravida berlangsung kira-kira 14 jam, sedangkan pada multigravida kira-kira 7 jam.

Berdasarkan uji " $\mathrm{t}$ " menggunakan Equal VariancesAssumed (diasumsikan kedua varian sama) dengan pengujian dengan menggunakan uji 2 sisi pada tingkat signifikansi $\alpha=0,05$. Berdasarkan 
tabel di atas didapatkan bahwa : dengan $t$ hitung $-0,295$ sedangkan $\mathrm{t}$ tabel pada $\mathrm{dk}$ n-2 (60) adalah 2.000 sehingga Ho diterima karena $-0,295<2,002$. Hal tersebut menunjukkan bahwa ada pengaruh pemberian stimulasi puting susu terhadap lama persalinan kala 1 di Puskesmas Gajahan. Hal ini sejalan dengan hasil penelitian yang pernah dilakukan oleh Pratiwi (2014) dengan judul pengaruh teknik pemberian stimulasi puting susu terhadap lama persalinan kala I di BPM Lasiyem Benis Jayanto Kecamatan Ceper dengan hasil ada pengaruh teknik pemberian stimulasi puting susu terhadap lama persalinan kala 1 dengan nilai $p$-value sebesar 0,006 $(\alpha=0,05)$. Selain itu, penelitian ini sejalan dengan pendapat Razgaitis, Lyvers (2010) dan thesi dari Mathews dimana stimulasi puting susu pada kala I mempengaruhi lama waktu kala I pada ibu primigravida. Hubungan antara stimulasi puting susu dengan lama kala II dilakukan oleh Istikhomah (2010) setelah dilakukan uji statistik Mann Whitney-U menggunakan SPSS mendapatkan hasil Asymp.sig 0,009 $<0,05$ yang berarti ada hubungan antara stimulasi puting susu kala II persalinan dengan terjadinya peningkatan kontraksi uterus.

Apabila terjadi rangsangan mekanisme ujung syaraf pada puting susu dan areola mammae, rangsangan itu nantinya akan diteruskan ke bagian hipotalamus dan menyebabkan hipofise posterior mensekresikan oksitosin ke dalam peredaran darah antara lain miometrium. Reseptor membran untuk oksitosin ditemukan baik dalam jaringan uterus maupun mammae, hormon oksitosin ini menyebabkan kontraksi otot polos uterus yang bisa mempercepat proses persalinan, sehingga digunakan dalam dosisfarmakologik untuk persalinan pada manusia.

Pada hasil penelitian Yunita (2007) di RSUD Surakarta dan BPS Suratinimenunjukkan bahwa terdapat perbedaan rata-rata waktu kelahiran plasenta pada kelompok subyek yang pada kala III persalinannya diberikan rangsangan puting susu dengan pemilinan dengan kelompok yang hariya diberikan MAK III saja tanpa pemilinan. Dari hasil penelitian ini rata-rata waktu kelahiran plasenta pada kelompok subyek yang kala III diberikan pemilinan adalah 4.450 menit, sedangkan pada kelompok subyek yang pada kala III tidak diberikan pemilinan adalah 7.032 menit. Dengan melihat hasil analisis bivariat di atas bahwa, kelompok ibu bersalin pada kala III antara yang dilakukan manajemen aktif kala III dan kelompok ibu bersalin pada kala III yang dilakukan manajemen aktif kala III dengan pemilinan waktu kelahiran plasenta terjadi perbedaan $(<0,05)$. Adapun beda waktunya adalah 2.582 menit lebih cepat dari kelahiran plasenta yang menggunakan MAK III ditambah pemilinan puting susu. Dari hasil penelitian tersebut dapat disimpulkan bahwa persalinan kala III yang menerapkan manajemen aktif kala III dengan pemilinan menunjukkan pengaruh yang signifikan dimana $\mathrm{p}<0,05(\mathrm{p} 0,00$; beda mean: 2.582). Penelitian tersebut didukung pendapat Huliana (2003) bahwa oksitosin dapat mempengaruhi jaringan otot polos agar berkontraksi sehingga dapat pula mempercepat lepasnya plasenta dari dinding rahim serta membantu mengurangi terjadinya perdarahan.

Berdasarkan teori dan kenyataan yang diperoleh dari hasil penelitian dapat dilihat bahwa waktu lama persalinan kala I pada ibu bersalin primigravida lebih 
cepat pada kelompok subyek yang kala I fase aktif diberikan rangsangan puting dibandingkan dengan kelompok yang kala I fase aktif tanpa rangsangan puting susu. Oleh karena itu, pemberian rangsangan puting susu kala I persalinan diperlukan agar waktu kelahiran lebih cepat.

\section{KESIMPULAN DAN SARAN}

Rata-rata lama persalinan kala I pada kelompok kontrol ibu bersalin primigravida yang tidak melakukan stimulasi puting susu ( mobilisasi) di Puskesmas Gajahan adalah 3.36 menit

Rata-rata lama persalinan kala I pada kelompok perlakuan ibu bersalin primigravida yang melakukan stimulasi puting susu di Puskesmas Gajahan adalah 3.21 menit.

Ada pengaruh stimulasi puting susu terhadap lama persalinan kala 1 dengan $\mathrm{p}$ value $=-0,295(\mathrm{p}<0,05)$ sehingga Ho diterima karena $-0,295<$ 2,002

Berkaitan dengan kesimpulan yang sudah dipaparkan di atas, maka peneliti dapat mengajukan beberapa saran. Diharapkan agar mengajarkan kepada ibu tehnik stimulasi, Bidan dapat meningkatkan pelayanan kesehatan khususnya dalam hal lama persalinan untuk mencegah kejadian kala 1 lama pada ibu bersalin dengan cara memberikan stimulasi puting susu pada persalinan kala 1, sehingga dapat mempersingkat persalinan kala 1. Hasil penelitian menunjukkan adanya pengaruh teknik pemberian stimulasi puting susu terhadap lama persalinan kala 1 yang dapat dijadikan salah satu alternatif untuk mempersingkat persalinan kala 1 .

\section{DAFTAR RUJUKAN}

Benson dan Pernoll. 2009. Buku Saku Obstetri dan Ginekologi. Ed 9. EGC. Jakarta.

Bobak. 2004. Buku Ajar Keperawatan Maternitas. EGC. Jakarta.

Chapman, V. 2006. Asuhan Kebidanan Persalinan dan Kelahiran. EGC. Jakarta.

Francis dan John. 2000. Endrokrinologi Dasar dan Klinik. EGC. Jakarta.

Mayasara S. 2011. Hormon Oksitosin. Retrieved from http//www.academia.edu/1832788/ hormon_oksitosin_oxytocin_horm one, diakses tanggal 5 Februari 2014 jam 08.00 WIB.

Pratiwi, Y.N. 2014. Pengaruh teknik pemberian stimulasi puting susu terhadap lama persalinan kala I di BPM Lasiyem Benis Jayanto Kecamatan Ceper

Prawirohardjo, S. 2009. Ilmu Kebidanan. Yayasan Bina Pustaka Sarwono Prawirohardjo. Jakarta.

SDKI. (2013). Retrieved from http://.www.health.kompas.com/re ad/2014/01/29/0910059/Tiga.Anca man.Penyebab.Kematian.Ibu.

diakses tanggal 12 Februari 2014 jam 09.00 WIB.

Simkin, P dan Ancheta. 2005. Buku Saku Persalinan. EGC. Jakarta.

Siswanto, dkk. 2013. Metodologi Penelitian Kesehatan dan Kedokteran.Bursa Ilmu. Yogyakarta.

Yunita FA. 2010. Pengaruh Pemberian Rangsangan Puting Susu dengan Pemilinan pada Menejemen Aktif Kala III Terhadap Waktu Kelahiran Plasenta. Jurnal Mahasiswa Kebidanan Surakarta 1(1): 40-47. 